\title{
„unter aller Würde der Societät“
}

(vorgetragen in Plenarsitzung am 4. 12. 2009)

Albrecht Schöne

In der Pauliner-Kirche gibt es eine Ausstellung über „Ursprung und Anfänge der Gelehrten Gesellschaften“, die Werner Lehfeldt am 8. November mit einem Vortrag über „Die europäische Akademieidee und ihre Ausformung in Göttingen" eröffnet hat. Deren Exponate wurden jetzt noch um ein Schriftstück ergänzt, das wohl auch unter den Mitgliedern unserer Akademie ein wenig in Vergessenheit geraten ist - obgleich es ihnen eine Ermahnung zukommen läßt, die durchaus einmal wieder Aktualität gewinnen könnte. Erlauben Sie mir deshalb, daß ich unser kollektives Gedächtnis mit einem kurzen Hinweis auffrische.

Zu den Mitgliedern der Göttinger Sozietät der Wissenschaften gehörten zur Zeit der französischen Revolution der Mineraloge Philipp Friedrich v. Dietrich, der als erster Maitre von Straßburg amtiert hatte, aber als Verteidiger einer konstitutionellen Monarchie dann Ende 1793 unter der Guillotine endete, und der Naturforscher Georg Forster, der als Mainzer Deputierter dem Pariser Nationalkonvent vorgeschlagen hatte, die linksrheinischdeutschen Gebiete der französischen Republik einzuverleiben, und 1794 als politischer Flüchtling in Paris gestorben ist. Ihretwegen geriet die Sozietät im April 1793 unter den Druck der Königlichen Regierung: Von sich aus sollte sie in Hannover beantragen, daß beide aus ihrer Mitgliederliste gestrichen, also ausgestoßen würden.

Der damalige Sekretär, der Altertumswissenschaftler Heyne, ließ daraufhin den Entwurf eines 'Pro Memoria'-Schreibens an die Regierung kursieren, in dem es hieß, dergleichen scheine ihm „unter aller Würde der Societät zu seyn“; man könne es „Höflingen und Speichelleckern zumuthen, aber keinem Corpus von Gelehrten“. Denn: „Die Societät ist eine gelehrte Gesellschaft, kein politisches Corpus, noch kein Club. Was mit den Mitgliedern in politischen Verbindungen und Verhältnissen vorgehet, gehet die Societät nichts an; denn diese Verhältnisse haben keine Beziehung auf das wissenschaftliche. Auch die Ehre der Societät tasten sie nicht an; sowenig als das Sittliche der Mitglieder, solange es keine bürgerliche Infamie nach sich zieht. Man kann aber Democrat u. Aristocrat, Bürger u. Sclav sein: und 
bleibt doch ein bürgerlich ehrlicher Mann. Will die Königliche Regirung gedachte Männer ausgestrichen haben: so mag sie es anbefehlen; und will sie, daß es öffentlich bekannt gemacht werden soll: so muß es angekündigt werden als auf Befehl Königlicher Regierung geschehen".

Diese couragierten Sätze also wurden den Mitgliedern der Sozietät im Umlaufverfahren vorgelegt. Forsters „politisches Betragen“ hat damals gewiß nicht nur Kästner mißbilligt, der das ausdrücklich vermerkte. Alle aber haben sich Heynes Vorschlag zu eigen gemacht und so den Ausschluß der beiden Jakobiner verhindert: Wrisberg, Kästner, Gmelin, Spittler, Beckmann, Gatterer, Meiners. Zuletzt „Ich ebenfalls Lichtenberg. und ich Blumenbach“. - Ein kleines Ruhmesblatt unserer Akademie. Allfällig zur Nachfolge empfohlen. 